\title{
Educação continuada coletivizada como espaço de investigação da socialização de professores
}

\section{Continuous education collectivized as a space of investigation of teachers' socialization}

\section{Márcia Regina do Nascimento Sambugari}

Doutora em Educação pela Pontifícia Universidade Católica de São Paulo (PUC-SP), professora adjunta da Universidade Federal de Mato Grosso do Sul (UFMS), Câmpus do Pantanal, Corumbá, MS - Brasil, e-mail: marciasambugari@yahoo.com.br

\section{Resumo}

Este artigo discute o papel dos cursos de formação continuada na socialização profissional de professores a partir do estudo exploratório que teve como finalidade contribuir com pistas para refinamento teórico-metodológico na utilização das categorias conceituais de Pierre Bourdieu como referencial teórico da pesquisa acerca da socialização profissional de professores em contextos de educação continuada. Como instrumentos de coleta de dados, 
a pesquisa contou com realização de entrevista com cinco professores, uso de questionário para caracterização desses sujeitos e sessões de observação num curso de formação continuada que ocorreu na ocasião da realização das entrevistas. A análise dos dados apontou a importância dos cursos de formação continuada para atualização, revigoramento e troca de experiências, mas também evidenciou a manifestação de não aceitação de alguns professores perante o que era proposto nos cursos. Tais constatações levaram a pensar na hipótese de que, de um lado, possam existir disposições duradouras incorporadas nos professores, ou seja, facetas de habitus relativas à profissão docente que comandam a sua visão sobre os cursos de formação continuada, levando-os a práticas que afetam a interpretação e assimilação de novas informações. Mas, por outro lado, é possível que também existam disposições que vão se alterando, vão se reestruturando a partir das relações de cada sujeito nas circunstâncias dos cursos. Nessa perspectiva, a educação continuada coletivizada pode ser considerada espaço propício para se investigar como se dá a socialização entre professores. $\mathrm{O}$ desvendamento desse espaço pode contribuir para a compreensão da profissionalização docente.

Palavras-chave: Educação continuada. Socialização. Professores.

\section{Abstract}

This article discusses the role of continuous formation courses in the teachers' professional socialization, starting from the exploratory study that had as purpose to contribute with tracks for theoreticalmethodological refinement in the use of Pierre Bourdieu's conceptual categories as a theoretical reference of the research concerning the teachers' professional socialization in contexts of continuous education. As instruments of data collection, the research counted with the accomplishment of interviews with five teachers; use of questionnaire for characterization of these subjects and observation sessions at a continuous formation course which happened in the occasion of the accomplishment of the interviews. The data analysis pointed the importance of continuous formation courses for updating, new vigor and interchange of experiences, but it also evidenced the non acceptance manifestation of some teachers 
before what was proposed at the courses. Such verifications made us think about the hypothesis that, on one side, there may be durable dispositions incorporated in the teachers, in other words, facets of habitus relative to the educational profession that command their vision on the continuous formation courses, taking them to practices that affect the interpretation and assimilation of new information. But, on the other hand, it is possible that there are also dispositions that go altering and restructuring starting from each person's relationships in the circumstances of the courses. In this perspective, the collectivized continuous education can be considered a favorable space to investigate how the socialization happens among teachers. Unmasking this space can contribute to the understanding of educational professionalization.

Keywords: Continuous education. Socialization. Teachers.

\section{Introdução}

Ao iniciar um processo de investigação acerca da socialização de professores em contextos de educação continuada, tornou-se necessário desenvolver um estudo exploratório, a fim de se ter uma aproximação maior com o objeto de pesquisa e delimitar melhor os sujeitos e as questões surgidas para posteriores estudos. A realização deste estudo inicial foi de suma importância, pois propiciou uma visão mais ampliada da realidade a ser investigada, trazendo informações relevantes que orientaram as decisões e os contornos necessários para o delineamento da pesquisa, pois, conforme salientam Alves-Mazzotti e Gwandsznajder (1998), essa fase permite ao pesquisador a definição dos procedimentos mais adequados à investigação em questão.

O objetivo central consistia em perceber qual o papel dos cursos de formação continuada na socialização profissional de professores e como esse espaço coletivo pode se constituir em campo propício na investigação da socialização de professores.

Nessa direção foi realizada uma revisão de estudos articulando três eixos: formação continuada, formação em serviço e socialização profissional 
de professores, evidenciando algumas constatações e contribuindo para a constituição do problema a ser investigado.

Foi possível verificar a incidência de estudos sobre formação continuada e formação em serviço e mesmo sobre socialização, quando se focalizam os aspectos pedagógicos da docência. Em todos esses focos há muita preocupação com a mudança na atuação dos professores, principalmente após o início do exercício profissional, porém, nenhum deles associando duas ou mais dessas facetas.

Assim, foi fundamental estabelecer certas relações entre esses focos, sobretudo porque alguns estudos apontaram para a dificuldade da mudança, certos esquemas em relação à profissão constituídos ao longo da vida sugerindo a possibilidade de que, já durante as atividades de educação continuada, ocorressem manifestações dos professores na direção de mudança dificultada, momentos em que os professores se posicionassem em relação a como seriam veiculados os conhecimentos nessas ações.

No contato com esses estudos ficou constatado que nos últimos anos a educação continuada vem sendo foco de muitas pesquisas e discussões, cujos temas giram em torno das diversas concepções de formação continuada, de análises de propostas sobre os processos de formação continuada e sobre o papel dos professores e da pesquisa nesse processo, dando ênfase ao processo crítico-reflexivo e ao processo formativo do professor de forma contínua, ou seja, ao longo de sua trajetória profissional, preferencialmente no espaço escolar, em serviço (ANDRÉ et al., 1999; BRZEZINSKI; GARRIDO, 2001; ZEICHNER, 1998).

Com relação às concepções de formação continuada, alguns estudos apontaram que esta não pode ser considerada uma formação que se restringe apenas a ações de reciclagens pedagógicas, mas um processo contínuo de desenvolvimento profissional do professor, de valorização da reflexão e da coletividade, tendo a escola como espaço privilegiado para que essa formação aconteça e seja capaz de articular todas as dimensões da profissão e propiciar mudanças em sua prática pedagógica (CANDAU, 1997; MARIN, 1995; PORTO, 2000).

Esses estudos levaram a pensar no pressuposto de que o modo de participação dos professores em cursos de educação continuada pode propiciar mudanças na forma de pensar ou agir, mas também pode não se alterar, talvez graças às propostas permeadas nesses cursos. Os professores possuem 
crenças e concepções que os acompanham ao longo de sua formação e que influenciam a prática educativa e o modo de ver o ensino (MARCELO GARCIA, 1998), ou seja, referenciais iniciais que foram construídos e internalizados por meio das relações na infância, na escolarização, que influenciam sua visão acerca da profissão e que são muito fortes nos professores mesmo depois de formados (MARIN, 1996).

Esses referenciais iniciais certamente têm influência na visão que o professor traz sobre os cursos de formação continuada e como a socializa. Assim, a educação continuada pode ser considerada espaço propício para se investigar como se dá a socialização entre os professores. $\mathrm{O}$ desvendamento desse espaço e dessa socialização pode contribuir na busca de novas propostas e ações de formação continuada que estejam centradas não somente na escola, mas no professor, na coletividade.

Outros estudos contribuíram para o refinamento e contornos necessários na pesquisa. Nos estudos sobre formação em serviço as discussões giram em torno das diferentes concepções (AQUINO; MUSSI, 2001); análises de propostas de programas e de projetos, fora ou no interior das escolas, focalizando também a formação a distância como uma modalidade significativa na formação continuada do professor (NASCIMENTO, 1996); o papel da coordenação pedagógica e da coletividade (ARAÚJO, 2000), mas também alertando sobre as condições que precisam ser dadas ao professor para que de fato a formação em serviço funcione e proporcione mudança em sua prática (GIOVANNI, 2003).

Esses estudos retrataram a formação de professores nas diversas categorias e em contextos diferenciados, abordando questões importantes com relação à formação contínua. Entretanto, o aspecto da socialização profissional do professor não foi abordado, demonstrando a necessidade de se investigar como os professores interagem em tais situações.

Com relação à temática da socialização profissional foram poucos os estudos realizados no Brasil, e focalizaram a aprendizagem da docência de professores iniciantes e experientes acerca de sua opinião sobre a socialização profissional, as influências no desenvolvimento profissional dos professores e o papel das instituições formadoras, a fim de perceber a contribuição dos cursos de formação na inserção e atuação do futuro professor. (LUDKE, 1994, 1996, 1998). Todavia, há necessidade de se estudar o que ocorre durante a veiculação de informações aos professores nas ações de educação continuada. 
Nessa mesma perspectiva da aprendizagem da docência, outros estudos com professores iniciantes focalizaram a organização escolar como aspecto relevante para a compreensão da socialização profissional dos professores iniciantes, por ser um espaço no qual desenvolvem várias estratégias para se socializarem (FREITAS, 2002); a compreensão do processo de "aprender a ensinar", a fim de conhecer os processos vividos pelas professoras na aprendizagem da docência (NUNES, 2002); a identificação de problemas enfrentados pelos professores no início da docência, bem como suas crenças acerca da profissão (MARCELO GARCIA, 1991) ou o desenvolvimento de saberes de professores iniciantes e recém-contratados, para explicitar que papel a formação inicial desempenha na formação desses professores que estão iniciando a docência (GUIMARÃES; SOUSA, 2004).

Apenas um trabalho investigou o processo de socialização num contexto de formação continuada (CHAMON, 2003), mas o estudo centrou-se na discussão da trajetória pessoal e profissional do professor, no processo de identificação desses professores com a profissão a partir de sua participação num programa de formação continuada.

Ao investigarem a socialização profissional, a preocupação desses autores estava no aspecto pedagógico da socialização profissional, isto é, como o professor aprende a ser professor e como ocorre a sua interação com a instituição de ensino à qual pertence. Tais estudos, apesar de focalizarem apenas a socialização de professores iniciantes ou em serviço, centrandose na aprendizagem da profissão, permitiram perceber que há trocas de informações entre os professores e as situações vivenciadas em cursos de formação continuada podem ser espaço fértil dessas trocas.

Conforme se constatou na revisão de estudos, há poucos trabalhos que focalizem essa socialização durante as atividades de educação continuada. Dessa maneira reforçou-se a relevância do desenvolvimento de uma pesquisa que investigasse os modos de reação dos professores perante as propostas veiculadas nas ações de educação continuada das quais participam. O foco central da pesquisa pautou-se nas seguintes questões: como os professores percebem a contribuição da educação continuada para a sua formação? Que modos de socialização são utilizados pelos professores durante as ações de educação continuada? 


\section{Percurso da pesquisa: procedimentos metodológicos}

Este estudo teve como objetivo identificar o papel dos cursos de formação continuada na socialização profissional segundo a visão de professores das séries iniciais do ensino fundamental, a fim de contribuir com pistas para o refinamento teórico-metodológico da pesquisa acerca da socialização de professoras em contextos de educação continuada.

Como instrumentos para coleta de dados, a pesquisa contou com uso de questionário para caracterização dos professores, realização de entrevista semiestruturada e também com sessões de observação num curso de formação continuada que ocorreu na ocasião da realização das entrevistas. A entrevista foi realizada com cinco professores do Ciclo I e Ciclo II do ensino fundamental ( $1^{a}$ a $4^{a}$ séries $)$ de uma escola da rede estadual de ensino de uma cidade localizada na região oeste do Estado de Mato Grosso do Sul.

Para a seleção desses professores foram utilizados alguns critérios, tais como: interesse em colaborar com o estudo; ser professor efetivo da rede pública estadual de Mato Grosso do Sul; atuar no Ciclo I ou II das séries iniciais do ensino fundamental; nível superior completo; entre 10 e 15 anos de atuação como professor, por considerar um período de experiências na profissão; estar participando de cursos de formação continuada no momento; e/ou ter participado de vários cursos de formação continuada.

O questionário foi aplicado no momento da entrevista com os cinco professores selecionados para este estudo, constituído de um roteiro contendo como foco alguns aspectos relevantes quando se utiliza a perspectiva teórica de Pierre Bourdieu, pois contribuem muito para se pensar o quanto as ações desenvolvidas e internalizadas no decorrer da vivência familiar e das relações sociais nas quais vão interagindo transformam e atualizam, ou não, as suas práticas, atitudes e formas de pensar. Dessa maneira, era importante obter informações sobre a estrutura familiar de cada entrevistado. Os dados obtidos por meio deste questionário foram sistematizados e organizados sob forma de quadros simples, agrupando as informações em três blocos:

- situação pessoal;

- aspectos sócio-culturais e sócio-profissionais da família e cônjuges;

- percurso escolar e profissional. 
Atenta aos cuidados salientados pela bibliografia, a entrevista foi gravada em áudio e logo em seguida transcrita. Após a transcrição das gravações as informações foram sistematizadas e organizadas em seis blocos:

- cursos de formação continuada de que já participaram;

- importância e contribuição dos cursos na vida profissional;

- conteúdos abordados nos cursos;

- escola: espaço de formação continuada;

- posicionamento dos professores diante dos cursos;

- brincadeiras e comentários dos professores durante os cursos.

A escolha em trabalhar com os professores da escola selecionada partiu da realidade peculiar das escolas da rede pública estadual dessa cidade, pois todos os professores eram efetivos. Outro fator refere-se às mudanças que eles vinham sofrendo graças às recentes reformas, tais como a mudança do regime seriado para o ciclado, o modelo de alfabetização centrado no construtivismo e a divulgação dos Parâmetros Curriculares, que exigem do professor novos ajustes no processo de ensino. A implantação do sistema de ciclos nas escolas da rede estadual de Mato Grosso do Sul ocorreu em 1998, ${ }^{1}$ sendo revisto em 2000, o que resultou em algumas modificações, ficando apenas as séries iniciais do ensino fundamental ( $1^{\mathrm{a}}$ a $4^{\mathrm{a}}$ séries) nesse sistema. Entretanto, somente em 2001 o sistema foi implantado na escola com a qual mantive contato em 2004. O ciclo funcionava apenas no período matutino, com cinco turmas sendo:

- uma turma de Ciclo I - Fase Inicial (1 ${ }^{\text {a }}$ série);

- uma turma de Ciclo I - Fase Final ( $2^{\mathrm{a}}$ série);

- duas turmas de Ciclo II - Fase Inicial ( $3^{a}$ série);

- uma turma de Ciclo II - Fase Final (4a série).

A escola tinha como proposta os professores seguirem os alunos durante os quatro anos. Isso era facilitado pelo fato de todos os professores serem efetivos.

A escola estava situada numa cidade de porte pequeno que possuía aproximadamente 12.300 habitantes, segundo o último senso do IBGE. ${ }^{2}$ Sua

\footnotetext{
${ }^{1}$ Resolução SED/MS n. 1.313 de 28 de dezembro de 1998.

${ }^{2}$ Informações disponíveis no site: http://www.ibge.gov.br.
} 
economia girava em torno da mineração de ferro, manganês, calcário, areia e argila, tendo o comércio como atividade principal. O município possuía apenas duas escolas da rede pública do Estado, duas particulares e quatro escolas municipais que atendiam à educação infantil, ensino fundamental e ensino médio.

As sessões de observação ocorreram na Jornada Pedagógica realizada no início de fevereiro de 2004 nos períodos matutino, vespertino e noturno. Aberta a todos que trabalhavam na escola, desde zeladores até diretores da rede estadual, contou com a participação de aproximadamente 747 professores de duas cidades. O curso foi promovido em colaboração com a Secretaria do Estado de Mato Grosso do Sul, pelo COUNE (Conselho das Unidades das Escolas Estaduais), composto por diretores, diretores adjuntos, coordenadores e assessores.

Ludke e André (1986, p. 25) salientam que, para a observação ser um "instrumento válido e fidedigno de investigação científica”, é necessário que haja um planejamento cuidadoso do trabalho e uma preparação rigorosa do observador, pois "planejar a observação significa determinar com antecedência o quê e como observar”. Dessa maneira, essa etapa de observação contou com a elaboração de um roteiro simples sem categorias definidas a priori, a fim de captar o máximo de informações sobre como ocorrem as relações entre os professores durante essa atividade de formação continuada.

O objetivo desse momento foi captarao máximo os comentários que os professores faziam entre eles durante os encontros e nos momentos do "cafezinho", a fim de trazer algumas pistas diante das questões já levantadas até o momento e que pudessem contribuir para outros estudos. Cada sessão de observação teve a duração de quatro horas. Foram realizadas quatro sessões de observações, totalizando 16 horas de permanência.

Durante a Jornada Pedagógica, como pesquisadora, sentei em vários lugares para que pudesse captar o máximo possível de comentários e expressões dos professores, e durante os intervalos para o cafezinho circulei entre várias "rodinhas" de professores. As observações foram registradas por meio de Diário de Campo composto de duas partes, conforme sugerem Bodgam e Biklen (1994, p. 167), a descritiva contendo o relato detalhado e descritivo de cada sessão de observação e a parte reflexiva com minhas anotações pessoais, comentários e pistas acerca das observações realizadas. 


\section{Os sujeitos da pesquisa: situação pessoal, familiar e profissional}

Com relação à situação pessoal dos sujeitos da pesquisa, dos cinco professores entrevistados, apenas um era homem, todos eram casados e tinham entre dois a quatro filhos. Eles se autoclassificaram como pertencentes à camada social média baixa e a idade variou entre 44 a 53 anos. Todos os professores nasceram na região, provenientes de famílias humildes, sendo quatro de família bem numerosa, tendo entre sete a dez irmãos. Esses dados evidenciaram a alta taxa de fecundidade dessas famílias e talvez isso possa sinalizar a escolha dessas professoras pelo magistério, já que a maioria era do sexo feminino.

Convém salientar que a divisão familiar da professora 3 era constituída de três irmãos paternos, dois irmãos maternos e três do casamento da família reconstituída. Dessa maneira, sua posição de nascimento era a sexta, contando todos os irmãos, porém era a primeira do casamento de seus pais. Um aspecto interessante a ser destacado nessa família é que, apesar da alta taxa de fecundidade, a professora 3 informou que apenas seu irmão mais novo não possuía nível superior, pois parou no ensino médio; os demais irmãos fizeram curso superior e sua mãe era professora e sempre incentivou os filhos a estudarem.

Com relação a aspectos sócio-culturais e sócio-profissionais da família, a análise dos dados apontou que os professores vieram de origem familiar humilde. As profissões de seus avós eram as de comerciante, maquinista e peão de fazenda, e possuíam pouca escolarização. Outro dado interessante é que parece que o papel da mulher era bem determinado, pois a maioria possuía pouca escolarização, algumas analfabetas, assumindo apenas o papel do cuidado da casa e dos filhos. Essas informações também poderiam oferecer pistas para se pensar sobre a opção desses professores pelo magistério, embora não seja o foco do presente estudo.

Essa realidade não mudou muito ao observar os dados relativos aos pais, que também exerciam profissões semelhantes, tais como funcionário público municipal, civil de Marinha, marteleteiro, ferroviário e mecânico. No entanto, parece que houve melhora com relação ao grau de estudo dos pais, apesar de pequena. Com relação à escolarização e profissão dos cônjuges dos entrevistados, parece que as relações matrimoniais não diferem muito de seus pais. Outra questão que chamou bastante a atenção se refere ao campo de atuação profissional das mães, 
que desempenhavam profissões consideradas próprias ao gênero, tais como enfermagem, costura e o próprio magistério.

Com relação à formação profissional, os cinco professores já possuíam nível superior, sendo três com formação em Pedagogia, uma em Letras e uma era formada em Educação Física. Apenas duas já fizeram especialização e uma começou a cursar em 2004.

O tempo de atuação profissional dos professores variou entre 14 a 27 anos. Apenas duas professoras trabalhavam também em instituição privada. Dois professores eram regentes ${ }^{3}$ que atuavam em turmas do Ciclo I e no Ciclo II das séries iniciais do ensino fundamental ( $1^{\mathrm{a}}$ e $3^{\mathrm{a}}$ séries) e três professores atuavam nos ciclos em áreas específicas, como Educação Física, Inglês e Educação Artística.

\section{O papel dos cursos de formação continuada na socialização profis- sional na visão dos professores: algumas constatações e indagações}

Apesar de reclamarem que há muito tempo não eram oferecidos cursos para os professores da rede estadual, todos os entrevistados apontaram ser importante participar de cursos de formação continuada, destacando ser um momento de atualização, de revigoramento, onde se aprendem coisas novas, novas técnicas, bem como um momento de "troca de experiências". Segundo o depoimento desses professores:

É muito importante. [...] você volta do curso com a cabeça mais aberta, tipo assim: você compreende mais a situação da sua clientela, que são os alunos (PROFESSOR 1).

É importante porque você se atualiza também. Você passa a lembrar de muitas coisas que ficam esquecidas muitas vezes no dia a dia, na vida corrida que nós temos. E você não percebe que está se esquecendo de certas situações (PROFESSORA 2).

Primeiro que renova, revigora o seu espirito de professor mesmo, porque tem horas que você fala: "puxa vida, porque en fui escolher ser professora?". Segundo porque você troca experiências (PROFESSORA 3).

\footnotetext{
${ }^{3}$ Professor regente refere-se ao professor titular da turma que trabalha com as disciplinas Português, Matemática, Ciências, História e Geografia.
} 
Olha, a capacitação que eu fiz. lá em A... eu procurei trabalhar dentro da sala de aula e surtiu efeito (PROFESSORA 4).

É importante a gente estar sempre participando de curso porque sempre tem uma coisa nova, uma técnica nova. Assim, uma coisa bem diferente daquelas que a gente vem seguindo bá muitos anos. Sempre tem umas técnicas mais atualizadas, diferentes daquilo que a gente usa (PROFESSORA 5).

Esses depoimentos suscitaram a seguinte questão: será que o modo de participação dos professores em cursos de educação continuada possibilita mudanças em sua forma de pensar ou de agir? As opiniões dos professores evidenciaram o reconhecimento da importância e a contribuição da educação continuada em sua vida profissional. Entretanto, no decorrer das entrevistas, ao comentarem sobre a realização da Jornada Pedagógica para iniciar as atividades escolares do ano letivo, dois professores aproveitaram o tempo para viajar, um alegando que os cursos oferecidos pela Secretaria da Educação eram sempre iguais e outro porque estava se aposentando.

Essa manifestação, à qual chamarei de "não aceitação" do curso, trouxe outras questões, tais como: por que será que alguns professores, no âmbito do discurso, falam da importância em participar de cursos de formação continuada, mas na prática, no momento da realização, possuem um posicionamento contrário àquele expresso no discurso? Será que essa "não aceitação" ocorre graças à própria manutenção de facetas do habitus desse professor, articulado à sua trajetória pessoal e familiar? Ou ainda, será que essa atitude de "não aceitação" não seria uma estratégia, um jogo de lutas simbólicas num campo determinado pelas políticas educacionais vigentes, com as quais ele não concorda, mas diz que "aceita" porque precisa sobreviver?

Ficou constatado que alguns professores manifestavam atitudes de não aceitação ao que estava sendo exposto, pois comentavam: "a proposta é legal, mas na minha sala não dá pra gente trabalhar assim” (PROFESSORA do Ciclo II participante da Jornada Pedagógica realizada em 2004); "isso é lindo e maravilhoso pra ele, mas eu vou dar a minha sala lotada pra ele e sem material pra ver como é bom pra tosse" (PROFESSORA do Ciclo II - participante da Jornada Pedagógica realizada em 2004); "eu vim aqui, mas nem sei o que vai ter aqui" (Professor de Biologia - participante da Jornada Pedagógica realizada em 2004).

Essas constatações e inquietações melevaram a pensar no pressuposto de que, de um lado, possam existir disposições duradouras incorporadas nos 
professores, ou seja, facetas de habitus que comandam a sua visão sobre os cursos de formação continuada, levando-os a práticas que acabam afetando a interpretação e assimilação de novas informações. Mas, por outro lado, também podem existir disposições que vão se alterando, vão se reestruturando a partir das relações e da autonomia de cada sujeito. Dessa maneira, há possibilidade de se consideraros cursos de educação continuada como espaços de reestruturação do habitus desses professores, sendo oportuna, portanto, a utilização de Pierre Bourdieu como referencial teórico na presente pesquisa, a fim de investigar se ocorre ou não e de que forma se dá essa reestruturação.

Para Bourdieu (2003, p. 53-54), habitus é um "sistema de disposições duráveis", isto é, um conjunto de tendências, de comportamentos que vão sendo adquiridos pelo indivíduo por meio das experiências práticas e das "condições materiais de existência", que são os preceitos, os conceitos, as preocupações produzidas primeiramente nas relações familiares e, posteriormente, nas demais agências de socialização com as quais ele irá se deparar no decorrer de sua vida, tais como a escola, clubes, igreja, vida profissional, etc. Essas disposições orientam as atitudes, as opções, enfim, as ações do indivíduo em seu agir cotidiano, que pode ser ora consciente, ora inconsciente, mas que está em constante reformulação.

Essas disposições duradouras vão se formando, no decorrer da trajetória de vida de cada professor, a partir das práticas culturais, ou seja, do “capital cultural", e vão compondo a identidade, a percepção desses professores, evidenciando práticas próprias da camada social à qual pertencem.

A noção de "capital cultural" elaborada por Bourdieu (2002,p. 74) refere-se aos códigos culturais, aos saberes ou bens culturais que o indivíduo vai adquirindo e a relação que ele mantém com esses conhecimentos, podendo existir na forma "incorporada", a partir da aquisição e internalização de conhecimentos, crenças, da cultura; "objetivada", por meio de aquisição de bens culturais; e "institucionalizada", que se dá por meio da certificação escolar. Esse conceito, articulado à noção de habitus, contribuiu no presente estudo no sentido de pensar sobre os cursos de formação continuada como possibilidade de ampliação desse "capital cultural" dos professores.

Essa possibilidade de reestruturação do babitus e de ampliação do capital cultural também ficou explicitada quando os professores se referiram às mudanças percebidas em sua vida profissional após a participação em cursos de formação continuada. Três professores apontaram que houve mudanças e duas destacaram que, embora ocorram, são poucas: 
[...] a mudança, ela é visivel, tá? Ela é visivel porque, como eu te disse, nós somos seres humanos e eu vejo que o ser humano por si só é um aprendizado até os finais dessa nossa passagem aqui (PROFESSOR 1).

A gente começa a aplicar o que você aprendeu. Você começa a desenvolver e você percebe que realmente a gente foge daquela rotina totalmente didática, voltada para o livro, e eles passam a viver conosco uma nova realidade. Então há uma diferença sim (PROFESSORA 4).

[...] mas a gente consegue mudar sim, atualizar um pouco, mudar as ideias, a maneira de ver, de avaliar o aluno principalmente, conviver com o aluno, aceitar certas coisas que a gente não aceitaria nos filhos (PROFESSORA 5).

Olha, com o passar do tempo você também se acomoda, entendeu? Mas você, como opção, tem que se autoavaliar, tem que ser crítica para seguir em frente, é diferente. Se você está fazendo um curso é pra alguma coisa, só que a gente da rede pública é muito difícil trabalbar, muito difícil (PROFESSORA 3).

A análise das observações apontou que o espaço de formação continuada éimportante para a socialização dos professores, pois há uma relação de troca entre eles. Isso ficou evidenciado nos comentários durante os intervalos para o cafezinho, momento em que os professores aproveitavam para conversar entre eles: "só nesses momentos que a gente se encontra" (PROFESSORA do Ciclo II - participante da Jornada Pedagógica realizada em 2004); "que bom que a gente se encontrou, precisava falar com voce" (PROFESSORA do Ciclo I - participante da Jornada Pedagógica realizada em 2004); "há muito tempo o Estado não faria algo assim" (Coordenadora pedagógica - participante da Jornada Pedagógica realizada, em 2004).

As professoras entrevistadas que participaram da Jornada salientaram a importância de participar desses cursos para um entrosamento entre os colegas, como também para aperfeiçoamento profissional. Esse estudo empírico permitiu observar, entre outros aspectos, que os cursos de formação continuada eram importantes para a socialização dos professores, pois havia uma relação de troca entre eles, e que poderiam ser considerados como espaço de socialização que poderia alterar ou não as atitudes, as ações dos professores.

\section{Considerações finais}

A realização deste estudo foi de suma importância, pois foram feitos os contornos necessários, confirmando a relevância do estudo, 
assim como contribuindo na definição do referencial teórico, utilizando o conceito de socialização a partir da categoria conceitual de habitus como a incorporação de formas de pensar e agir duradouras que engendram as ações das professoras, contrapondo-se às exigências das ações de educação continuada. Estas poderiam levar ou não à alteração do habitus no que se refere a facetas da docência. Esse estudo permitiu observar a importância dos cursos de formação continuada para a troca de experiência entre os professores e a oportunidade de que tal espaço de socialização contribua para alterar a atitude desses profissionais.

A aproximação das discussões sobre as imagens e crenças que o professor traz internalizadas e que influenciam a sua visão permitiu constatar que as categorias habitus e "capital cultural" propostos por Pierre Bourdieu constituiriam quadro interpretativo muito interessante para auxiliar na compreensão da socialização de professores em contextos de educação continuada. Tomando como base a perspectiva teórica de Bourdieu, a socialização pode ser concebida como um processo de incorporação de práticas, de atitudes e também percepções que são engendradas desde a infância nas relações familiares, bem como nas diversas agências de socialização com as quais o indivíduo vai interagindo no decorrer de sua vida, permitindo que suas ações se atualizem ou não a partir das novas situações e interações vivenciadas.

Assim, a primeira hipótese do estudo foi elaborada considerando a educação continuada organizadora de situações de socialização profissional que ocorre em duas vias: ao mesmo tempo em que veicula novos conhecimentos a serem incorporados pelos professores, buscando alteração de suas práticas pedagógicas, é também um espaço de interação, de trocas, no qual eles se expressam, demonstrando atitudes de aceitação ou de rejeição diante das novas situações que vão sendo disseminadas entre eles.

Essas atitudes levaram a elaborar outra hipótese: de que, de um lado, existam disposições duradouras incorporadas nos professores, ou seja, habitus que comanda a sua visão sobre os temas veiculados nas ações de formação continuada, levando-os a modos de socialização que acabam afetando a interpretação e assimilação de novas informações. Mas, por outro lado, também podem existir outras disposições que vão se alterando, se reestruturando a partir das relações no grupo.

Alguns pontos foram analisados neste artigo e deve-se destacar a relevância dessa hipótese inicial na coleta, descrição e análise dos dados, 
permitindo chegar à compreensão da relevância de estudos sobre processos de socialização expressos tanto pelas situações quanto pelos modos de reação de professores, sejam positivos ou negativos, em relação a ações de formação continuada.

Levar em conta essas “disposições”, essas “estruturas incorporadas" pelos professores, é muito importante para entender como os modos de socialização e de troca vão ocorrendo dentro dos cursos. Entretanto, este é um dado não considerado como elemento de interferência para o aproveitamento, ou não, na realização dos cursos. Dessa maneira, os cursos de formação continuada precisariam estar atentos a essa realidade dos professores e, talvez, a atenção à interação que eles fazem entre si possa trazer pistas para se repensar os cursos de formação continuada, que sejam pautados a partir das necessidades, expectativas e condições concretas dos professores, de modo a contribuir para seu desenvolvimento profissional.

\section{Referências}

ALVES-MAZZOTI, A. J.; GEWANDSZNAJDER, F. O método nas ciências naturais e sociais: pesquisa qualitativa e quantitativa. Rio de janeiro: Thomson Pioneira, 1998.

ARAÚJO, I. A. Educação continuada: traços, trilhas e rumos da coordenação pedagógica. 2001. 144 f. Dissertação (Mestrado em Educação) - Faculdade de Educação de Brasília. Universidade de Brasília, Brasília.

ANDRÉ, M. E. D. A. et al. Estado da arte da formação de professores no Brasil. Educação e Sociedade, v. 20, n. 68, p. 301-309, 1999.

AQUINO, J. G.; MUSSI, M. C. As vicissitudes da formação docente em serviço: a proposta reflexiva em debate. Educação e Pesquisa, v. 27, n. 2, p. 211-227, 2001.

BOGDAN, R.; BIKLEN, S. K. Investigação qualitativa em educação: uma introdução à teoria e aos métodos. Porto: Porto Editora, 1994.

BOURDIEU, P. Os três estados do capital cultural. In: NOGUEIRA, M. A.; CATANI, A. (Org.). Escritos de educação. Petrópolis: Vozes, 2002. p. 71-79.

BOURDIEU, P. Esboço de uma teoria da prática. In: ORTIZ, Renato. A sociologia de Pierre Bourdieu. São Paulo: Olho d'água, 2003, p. 39-72. 
BRZEZINSKI, Í.; GARRIDO, E. Análise dos trabalhos do GT formação de professores: o que revelam as pesquisas do período 1992-1998. Revista Brasileira de Educação, n. 18, p. 82-100, 2001.

CANDAU, V. M. Formação continuada de professores: tendências atuais. In: CANDAU, V. M. (Org.). Magistério: construção cotidiana: Petrópolis: Vozes, 1997. p. 51-68.

CHAMON, E. M. Q. O. A formação continuada e o processo de socialização profissional de professores. In: CONGRESSO BRASILEIRO DE SOCIOLOGIA, 11., 2003, Campinas. Anais... Campinas: Unicamp, 2003. p. 115.

FREITAS, M. N. C. Organização escolar e socialização profissional de professores iniciantes. Cadernos de Pesquisa, n. 115, p. 155-172, 2002.

GIOVANNI, L. M. O ambiente escolar e ações de formação continuada. In: TIBALLI, E. A.; CHAVES, S. M. (Org.). Concepções e práticas de formação de professores: diferentes olhares. Rio de Janeiro: DP\&A, 2003. p. 207-224.

GUIMARÃES, V. S.; SOUSA, L. F. E. C. P. A socialização profissional e o aprendizado da profissão docente. In: ENCONTRO NACIONAL DE DIDÁTICA E PRÁTICA DE ENSINO: CONHECIMENTO LOCAL E CONHECIMENTO UNIVERSAL, 12., 2004, Curitiba. Anais... Curitiba, PUCPR, 2004. p. 1743-1753. 1 CD-ROM.

LUDKE, M.; ANDRÉ, M. E. D. Pesquisa em educação: abordagens qualitativas. São Paulo: EPU, 1986.

LUDKE, M. A socialização profissional de professores. Caxambu: Anped, 1994. (mimeo).

LUDKE, M. Sobre a socialização profissional de professores. Cadernos de pesquisa, n. 99, p. 5-15, 1996.

LUDKE, M. Socialização profissional de professores: as instituições formadoras. Relatório final de pesquisa. Rio de Janeiro: Universidade Federal do Rio de Janeiro, 1998. Disponível em: <http://www.cfch.ufrj.br/nec/pesquisa2. html/>. Acesso em: 8 jun. 2003.

MARCELO GARCIA, C. Aprender a enseñar: um estúdio sobre el proceso de socialización de profesores principiantes. Madrid: Centro de Publicaciones del Ministério de Educación y Ciência: C.I.D.E., 1991. 
MARCELO GARCIA, C. Formação de professores: o conhecimento sobre o aprender e ensinar. Revista Brasileira de Educação, n. 9, p. 51-75, 1998.

MARIN, A. J. Educação continuada: introdução a uma análise de termos e concepções. Cadernos CEDES, n. 36, p. 13-20, 1995.

MARIN, A. J. Propondo um novo paradigma para formar professores a partir das dificuldades e necessidades históricas nessa área. In: REALI, M. A.; MIZUKAMI, M. das G. N. Formação de professores: tendências atuais. São Carlos: EDUFSCar, 1996. p. 153-165.

NASCIMENTO, M. das G. C. de A. A escola como espaço de formação continuada de professores: análise de uma experiência. 1996. 132 f. Dissertação (Mestrado em Educação) - Pontifícia Universidade Católica do Rio de Janeiro, Rio de Janeiro, 1996.

NUNES, J. B. C. O processo de socialização na profissão docente. In: ENCONTRO NACIONAL DE DIDÁTICA E PRÁTICA DE ENSINO: IGUALDADE E DIVERSIDADE NA EDUCAÇÃO, 11., 2002, Goiânia. Anais... Goiânia: multipolo, 2002. p. 1-24. 1. CD-ROM.

PORTO, Y. da S. Formação continuada: a prática pedagógica recorrente. In: MARIN, Alda Junqueira. (Org.). Educação continuada. Campinas: Papirus, 2000. p. 11-37. (Coleção Magistério: formação e trabalho pedagógico).

ZEICHNER, K. Tendências da pesquisa sobre formação de professores no Estados Unidos. Revista Brasileira de Educação, n. 9, p. 76-87, 1998.

Recebido: 16/04/2010 Received: 04/16/2010

Aprovado: $21 / 06 / 2010$ Approved: 06/21/2010 